\title{
O SAGRADO E O PROFANO EM ALBERTO CAEIRO
}

\author{
Isaac Newton Almeida Ramos ${ }^{1}$
}

RESUMO: Alberto Caeiro funda o paganismo superior na obra de Fernando Pessoa. Esse procedimento evidencia-se no livro $O$ guardador de rebanhos, em particular, no canto VIII. Ele apresenta a humanização de Jesus Cristo, que retorna como menino. O sagrado e o profano se alimentam da mesma matéria poética.

PALAVRAS-CHAVE: Alberto Caeiro, modernidade, sagrado, profano e humanização.

RÉSUMÉ: Alberto Caeiro trouve le paganisme profond dans l'œuvre de Fernando Pessoa. Cette procédure est évidente dans le livre $O$ guardador de rebanhos, en particulier, à la VIII. Il présente l'humanisation de Jésus-Christ, qui revient comme un garçon. Le sacré et le profane se nourrissent de la même matière poétique.

MOTS-CLÉS: Alberto Caeiro, modernité, sacré, profane et humanisation.

Fernando Pessoa é considerado pela História da Literatura Ocidental um dos dois grandes nomes da poesia em língua portuguesa. O outro é Camões. Em um estudo mais sério que quisesse apontar traços de modernidade na poesia portuguesa, ao longo dos séculos, seria possível verificar que muitos poetas que antecederam Pessoa contribuíram decisivamente para as inovações temáticas, estruturais e mesmo para a criação dos heterônimos pessoanos. Não seria heresia afirmar que a renovação da lírica portuguesa vem desde a lírica trovadoresca, passando pelos cancioneiros maneiristas, barrocos, românticos, realistas, simbolistas até chegar à geração de Orpheu. Ao longo desse percurso, ocorreram inovações no aspecto formal, motivo temático, abordagens filosóficas, diálogos com a tradição clássica, germinação das questões do eu, a poesia revolucionária e metafísica de Antero de Quental no realismo, a modernidade lírica de Cesário Verde na Geração de 70 e o simbolismo, a renovação lírica e as poéticas de António Nobre, Camilo Pessanha e Manuel Laranjeira.

\footnotetext{
${ }^{1}$ Doutorando em Estudos Comparados de Literaturas de Língua Portuguesa (FFLCH-USP). Professor da Universidade do Estado de Mato Grosso UNEMAT. Bolsista CAPES. 
Dentre esses poetas destacam-se Antero de Quental, com a poesia revolucionária e metafísica (um dos temas prediletos de Pessoa e alguns de seus heterônimos) e Cesário Verde, um dos grandes nomes da modernidade lírica da geração de 70. As histórias da literatura portuguesa não costumam mostrar esse percurso evolutivo, o qual é de fundamental importância para entender a obra de Fernando Pessoa e o estudo dos seus heterônimos.

Um breve exemplo da superficialidade com que muitas vezes é tratada a obra de Pessoa nos manuais didáticos é o fato de raramente ser citado que são 72 e não 4 os heterônimos criados por esse poeta português. É importante lembrar que podem ser mais de 72, posto que o espólio da obra de Pessoa continue a ser explorado 74 anos após a sua morte (morreu em 30 de novembro de 1935, com 47 anos, três dias depois de ter sido internado com cólica hepática).

Antes de passar ao objeto de estudo deste texto, é pertinente citar a famosa carta redigida por Pessoa em 13 de janeiro de 1935 - 10 meses antes de sua morte - a Adolfo Casais Monteiro, na qual faz referência ao "dia triunfal" de sua vida, o 8 de março de 1914. Esta seria a data que teria escrito "de pé", apoiado numa cômoda alta, "trinta e tantos poemas" de $O$ guardador de rebanhos, atribuídos a Alberto Caeiro. Provavelmente, esse é um dos principais mitos criados propositalmente pelo poeta e amplificado pela historiografia literária. Registre-se que o número de poemas, no referido livro, chega aos 49. Ivo Castro, organizador de uma edição crítica da obra de Caeiro, sustenta que no "dia triunfal" o poeta teria escrito "apenas" 19 poemas. Para chegar aos 49, dez textos produzidos antes de 8 de março seriam atribuídos a Caeiro e incorporados ao volume; os demais o poeta teria escrito depois. Não acredito nessa estória. Ainda mais quando, dentre eles, consta o longo e polêmico canto (a partir deste momento, adotarei a terminologia canto em lugar de poema) VIII, que aqui será objeto de análise.

Após esse prelúdio textual, passo ao estudo comparativo entre o canto de Caeiro e o texto bíblico com o intuito de apontar as marcas de modernidade presentes no referido canto. Este caminho pode facilitar a discussão do chamado "paganismo superior", atribuído a Caeiro, que se configura como uma das marcas de modernidade. "O paganismo é a religião que nasce da terra - que nasce da atribuição a cada objeto de sua realidade 
verdadeira", explicava Antonio Mora (filósofo e sociólogo, teórico do Neopaganismo) no seu $O$ regresso dos deuses.

O canto em questão é considerado por vários estudiosos e até por Fernando Pessoa, em suas Páginas íntimas e de Auto-interpretação, como o mais radical e antiespiritualista. "Dentre os heterônimos de Pessoa, Caeiro é aquele que assume de maneira mais marcante e radical a contestação do mito e do poder representativo da linguagem" (SEGOLIN, 1989, p.252). Esse canto faz parte dos chamados textos que o próprio Pessoa não escreveria:

Criou-as e passou a atribuir-lhes "poemas vários que não são como ele, nos seus sentimentos e idéias, os escreveria", poemas nos quais não se devem buscar idéias ou sentimentos dele, Pessoa: "pois muitos deles exprimem idéias que não (aceita), sentimentos que nunca (teve)." Exemplifica esta afirmação com o poema oitavo do "Guardador de Rebanhos cuja blasfêmia infantil e anti-espiritualismo absoluto", ele em sua própria pessoa, nunca usaria. (BERARDINELLI, 1985, p.263)

A face pagã de Caeiro está presente praticamente em todo o canto VIII e serve, sobretudo, para imprimir uma marca forte nesse que foi considerado o mestre dentre os heterônimos pessoanos. Álvaro de Campos afirma: “o meu mestre Caeiro não era um pagão: era o paganismo" (OP, 1998, p.248)². Tal afirmação hiperboliza o sujeito pagão, transformando-o de adjetivo em substantivo. No mesmo parágrafo, Campos observa que "em Caeiro não havia explicação para o paganismo; havia consubstanciação" (op. cit., p.248). Seria esse o motivo do próprio Caeiro não aceitar o rótulo de materialista? Um dos heterônimos de Pessoa, Ricardo Reis, diz: "A obra de Caeiro representa a reconstrução integral do paganismo, na sua essência absoluta, tal como nem os gregos nem os romanos, que viveram nele e por isso o não pensaram, o puderam” (apud Berardinelli. op. cit. p.266). Mudando um pouco o rumo da abordagem, de forma um tanto equivocada, Benedito Nunes (1969, pp.220-221) chega a afirmar que como se fosse um discípulo moderno e ocidentalizado do Zen-budismo, Caeiro adestra-se a ter uma visão do mundo, não turbada pela necessidade de reflexão - visão de um olhar só, não desdobrável num outro, reflexivo, que aprecia e julga aquilo que está vendo. Enquanto isso, Rinaldo Gama (1995, p.92) reproduz impressão de Haroldo de Campos nas suas "Notas à Margem de uma análise de

\footnotetext{
${ }^{2}$ Neste trabalho adoto a terminologia OP para Obra Poética. Aqui trecho de um Posfácio escrito por Álvaro de Campos, intitulado "Notas para a recordação do meu mestre Caeiro".
} 
Pessoa"3, que não hesita em afirmar que o ensaio "Os Oxímoros Dialéticos..." - escrito por Jakobson - se constitui no exame mais rigoroso e criador jamais feito de um poema - "e, por extensão, da poética mesma" - de Fernando Pessoa. Gama (1995) ainda aponta que a partir desse estudo de Jakobson, a crítica centrada na análise do texto propriamente dito tomou à frente da exegese do poeta. Citou os nomes de Fernando Segolin e Eduardo Lourenço os quais teriam atingido novo estágio da crítica pessoana. Ocorre que, deste último, ele ressalva que o estudioso português ainda atende a certas inclinações de ordem psicanalítica. Discordo do ponto de vista de Gama, que se alinha a uma crítica semiótica peirceana. A minha discordância não é por ele seguir essa linha. Isso não é relevante nesse momento. O que importa destacar é que Lourenço é um dos principais nomes da crítica literária portuguesa, com estudos fulcrais como Pessoa Revisitado - Leitura Estruturante do Drama em Gente (1973) e O Labirinto da Saudade: Psicanálise Mítica do Destino Português (1991). Nesse último título, por exemplo, ele traça um paralelo entre as obras Pátria de Junqueiro, Mensagem de Pessoa e Pátria-Saudade de Teixeira de Pascoaes. Para melhor ilustrar a sua crítica, destaco a seguinte passagem:

Entre o homem e a Realidade há uma osmose contínua, como se um e outra fossem anverso e reverso de uma única realidade original, cujo ser e perfil só negativamente podem ser aludidos. [...] O universo inteiro é uma Metáfora viva em permanente metamorfose daquilo que existente, sabido e conhecido, conferiria à Natureza e ao Homem autêntica realidade. Por isso mesmo só o absolutamente real é real. Fernando Pessoa passará a vida a querer sair desta visão de fogo sem jamais o conseguir. (LOURENÇO, 1991, p.101).

A citação acima de Lourenço é perfeita para fechar as impressões gerais apresentadas nesse artigo sobre Fernando Pessoa e, sobretudo, Alberto Caeiro. Afinal, o paganismo do poeta de $O$ Guardador de Rebanhos, como disse Nunes (1969, p.221), “é fundamentalmente a inocência da alma”. Após essas observações críticas passo à abordagem de alguns dos 157 versos do Canto VIII. Ressalto que, o poema como um todo, representa uma cosmovisão do paganismo de Caeiro. $\mathrm{O}$ eu poético relata uma visão onírica supostamente tida com o menino Jesus. Isso pode ser observado desde a primeira estrofe: "Num meio-dia de fim de primavera/ Tive um sonho como uma fotografia". A primavera,

\footnotetext{
${ }^{3}$ Linguística. Poética. Cinema. p.196.
} 
além de ser uma estação amena, em sentido figurado representa a infância e a juventude. E nela desabrocha toda a natureza. Utilizando-se de uma comparação (sonho e fotografia), ele aproxima o onirismo (sensação de irrealidade) com a realidade captada pelo diafragma de uma lente de uma câmara fotográfica (sensação de imutabilidade). Também poder-se-ia dizer sobre uma realidade sensitiva ou modo sensitivo de ver as coisas, a partir da tradição cristã. Seria a própria dessacralização do sujeito real em um sujeito poético: "Vi Jesus Cristo descer à terra./ Veio pela encosta de um monte/ Tomado outra vez menino". É como se o sujeito poético promovesse uma regressão temporal e corporal e ao mesmo tempo em que ele dessacraliza o texto bíblico, sacraliza o texto literário. São marcas textuais evidentes que imprimem traços da e na modernidade.

O devir poético se apresenta incrustado e inscrito no canto do texto sagrado e se desdobra em versos gozando de um momento profano. É como se a realidade literária se constituísse em um espaço imagético em que o desapego ao texto sagrado se converte em um Cristo despregado da cruz "a correr e a rolar-se pela erva/ e a arrancar flores para as deitar fora/ e a rir de modo a ouvir-se de longe". Esse deslocamento do espaço sagrado para o terreno - Jesus subiu aos céus e pregou no monte, no texto bíblico; no canto, ele vê Jesus descer à terra e vir pela encosta - mostra que o descolamento da consciência cristã funciona como um anteparo para a realidade poética que está por vir.

As veias abertas do paganismo superior caeiriano se evidenciam a partir do segundo parágrafo: "Tinha fugido do céu./ Era nosso demais para fingir/ De segunda pessoa da Trindade". Caeiro escava de maneira fácil a memória fóssil do cristianismo. Os valores cristãos são postos à prova: "Nem sequer o deixavam ter pai e mãe/ Como as outras crianças./ O seu pai era duas pessoas -/ Um velho chamado José, que era carpinteiro,/ E que não era pai dele;/ E o outro pai era uma pomba estúpida,/ A única pomba feia do mundo/ Porque não era do mundo nem era pomba./ E a sua mãe não tinha amado antes de o ter". No cântico poético, os fatos são como que cinzelados para atender a um desejo profano, não com o intuito de deturpar a realidade do texto consagrado, mas, sobretudo, para revelar a visão de um Cristo humanizado. Mesmo quando aparentemente se desmitifica um símbolo judaico-cristão como a pomba que, com o Novo Testamento representa o Espírito Santo - sendo fundamentalmente, um símbolo de pureza, de 
simplicidade e que no canto passa a ser "uma pomba estúpida". A inversão da aparência (beleza versus feiúra) não remete necessariamente a uma depreciação do ser. "Belo e feio já não são valores opostos, mas digressões de estímulos. Sua diferença objetiva é eliminada, como a diferença entre verdadeiro e falso" (FRIEDRICH, 1991, p.77). Baudelaire, antes mesmo de Flores do mal e de Rimbaud, antecipou a estética do feio. Não é o inverso da história bíblica que Caeiro busca e sim o avesso do imagético pré-concebido. Melhor seria dizer que se trata de um trabalho de desconstrução de arquétipos poéticos. Ou, como ensina Pessoa em Mensagem: "O mito é o nada que é tudo" (OP, p.72).

Para construir seu canto, Caeiro dialoga com quatro evangelhos: João, Lucas, Marcos e Mateus. Praticamente, todos eles se atem à mesma coisa, no entanto, há sutis diferenças entre cada um. Dentre os apóstolos de Jesus Cristo, João foi o mais íntimo, um grande amigo. Ele testemunhou os milagres e é o mais detalhado em sua narrativa. Lucas não teria testemunhado praticamente nada. O seu evangelho é escrito bem depois. Tomou muito cuidado para descrever. Pode-se dizer que ele se prende ao que foi feito por João. Marcos e Mateus também se baseiam no primeiro. Possivelmente, por ter escrito depois que os outros, Mateus seja mais histórico. Ele se prende não só ao que Jesus estava passando. Mateus também se baseia no evangelho de Marcos. Este último esteve presente na maioria das ações. Talvez aí resida a coincidência do ponto de vista narrativo empreendido pelo eu poético caeiriano. Da mesma forma que Marcos se coloca como um dos apóstolos, Caeiro se mostra íntimo do menino Jesus. E, por isso, os dois o apresentam de forma direta. No canto, além das referências aos citados evangelhos também há uma passagem do Gênesis e uma parábola.

$\mathrm{Na}$ primeira estrofe do canto de Caeiro há uma referência ao nascimento de Jesus Cristo (Lucas 2) e, em seguida, parte para a fase de menino (Mateus, 2):

Depois de sua partida, um anjo do Senhor apareceu em sonhos a José e disse: "Levanta-te, toma o menino e sua mãe e foge para o Egito; fica lá até que eu te avise, porque Herodes vai procurar o menino para o matar.” (BÍBLIA SAGRADA AVE MARIA, 2000, p.1286)

O trecho acima pode ser colocado ao lado destes versos de Caeiro: "A correr e a rolar-se pela erva/ E a arrancar flores para as deitar fora/ E a rir de modo a ouvir-se de 
longe". Trata-se da imagem de Cristo humanizado, gozando o direito de ir e vir fazendo o que qualquer criança faria.

Pessoa nega a existência de Jesus como personalidade histórica e considera a religião cristã como sendo a obra do apóstolo Paulo: estas idéias quanto ao Cristianismo são um reflexo fiel da ala estrema da teologia liberal do séc. XIX e, por outro lado, dos filósofos do ateísmo." (LIND, s/d., p.109)

Na primeira estrofe, quanto ao aspecto morfossintático, há predominância de verbos que indicam ação (descer, veio, correr, rolar, arrancar, rir, ouvir). Sintaticamente, a estrofe começa com um adjunto adverbial de tempo, sendo que em todos os períodos há elipse do sujeito (eu). Nas orações, as frases são de ordem direta - acompanhando o tom narrativo do poema em prosa - e várias coordenadas. É importante lembrar que o poema em prosa é uma das marcas da modernidade.

A segunda estrofe, que vai do verso 9 ao 26, inicia-se com o verso "tinha fugido do céu”. Refere-se o poeta ao Evangelho de São Marcos, 16, na parte em que Jesus deixa o sepulcro. Há uma inversão aqui, pois Jesus subiu aos céus para tomar o lugar dele de direito; ou seja, ao lado do pai. No poema, Ele foge do céu e vem para terra. Por isso, a inversão de valores, que se caracteriza em uma desordem, uma desmitificação da figura cristã. Dos versos 10 ao 15, a ironia pagã se acentua e o eu poético deixa antever que no céu tudo é falso, em desacordo com flores e árvores e pedras. E a natureza, como costuma ser nos versos de Caeiro, mostrada como ela é. Caeiro apresenta o espaço físico da natureza, sem sobressaltos. Os mistérios do universo se fundem em conhecimento do ser, na verdade o não-ser. A não-filosofia, a desnatureza do verbo. A propagação do paganismo. Isso pode ser percebido nos versos 16 e 17: "e subir para a cruz, e estar sempre a morrer/ Com uma coroa toda à roda de espinhos", os quais remetem ao evangelho de Marcos.

Morfologicamente, os verbos de ligação predominam. Com isso, há muitas referências nominais. Sintaticamente, imperam orações subordinadas reduzidas. A marca da temporalidade é forte e anunciativa. Estilisticamente, pelo menos duas comparações " $\mathrm{E}$ até com um trapo à roda da cintura/ Como os pretos nas ilustrações./ Nem sequer o deixavam 
ter pai e mãe/ Como as outras crianças" e uma ironia metafórica "E o outro era uma pomba estúpida" compõe a estrofe.

A terceira estrofe, constituída por apenas cinco versos, apresenta uma imagem depreciativa de Maria utilizando-se, mais uma vez, da ironia: "Não era mulher: era uma mala/ Em que ele tinha vindo do céu”. E estende esse recurso estilístico, de forma enfática, ao dizer que o menino que nunca tivera pai para amar com respeito, queriam que ele pregasse a bondade e a justiça. Morfologicamente, a estrofe inicia-se com uma negação composta por verbos de ligação (era) e depois seguem verbos de ação (tinha vindo, queriam, nascera, tivera, amar, pregasse) que remetem simbolicamente ao enviado.

Caeiro no Canto VI, do mesmo "O Guardador de Rebanhos", diz: "Pensar em Deus é desobedecer a Deus, / Porque Deus quis que o não conhecêssemos, / Por isso se nos não mostrou"... (OP, 1998, p.208). Pessoa, no livro Cancioneiro se mostra agradecido a Deus pela sua existência, quando afirma: "Sou grato Ao que do pó que sou/ Me levantou" (op.cit., p.164). Ele se refere ao livro do Gênesis. Ainda Pessoa, no poema "Liberdade", ironiza: "O mais do que isto/ É Jesus Cristo, / Que não sabia nada de finanças/ Nem consta que tivesse biblioteca" (idem, p.188).

Dentro da mesma temática, no referido Cancioneiro, Pessoa diz: "Mas antes era o Verbo, aqui perdido/ Quando a Infinita Luz, já apagada, /Do Caos, chão do Ser, for levantada" (idem, p.190). Neste fragmento o verbo pode ser entendido como a palavra de Jesus Cristo ou como a palavra do poeta. Este verbo (palavra), seja qual for, se perde no momento em que a luz infinita, porém apagada (silêncio), for erguida do chão da existência; isso implica que ela pode ser dita pelo poeta ou por Jesus Cristo.

$\mathrm{Na}$ quarta e quinta estrofes, predominam verbos de ação e mostram a "fuga" do menino Jesus para morar na aldeia com o eu poético. "Aproveitando de uma distração de Deus, que estava a dormir/ E o Espírito Santo andava a voar,/ Ele foi à caixa dos milagres e roubou três". Para poder gozar mais tempo da situação de menino, providenciou esses milagres para distrair a humanidade. A tradição cristã exige a confirmação de pelo menos três milagres para que uma pessoa se torne santo(a). Ele o fez. Essa pequena distração roubar três milagres - possibilitou que ele continuasse as atividades a que se havia proposto: "Chapinha nas poças de água,/ Colhe as flores e gosta delas e esquece-as./ Atira 
pedras aos burros,/ Rouba a fruta dos pomares/ (...) Corre atrás das raparigas/ (...) E levanta-lhes as saias".

No início da quinta estrofe há o ensinamento do olhar: "A mim ensinou-me tudo./ Ensinou-me a olhar para as cousas". O olhar é o órgão de eleição de Caeiro. "Transparece o paradigma imagético erguido nos labirintos de uma semântica do olhar cotidiano. O olhar é referência, mais do que isso é um estado de ser, um estado de permanência. Para o olhar da criança não importa o significado, o que importa é a imagem” (RAMOS, 2004, p.30).

A sexta estrofe apresenta as impressões críticas do menino Jesus. "Se já estava nos ensinamentos de Caeiro que, desde o poema I, evoca a infância, e, no VIII, também impactante, constrói seu 'Menino Jesus' como arquétipo da infância e seu viver lúdico" (GARCEZ, 2007, pp.271-2). Sobre Deus, diz: "ele é um velho estúpido e doente,/ Sempre a escarrar no chão/ E a dizer indecências". Sobre a Virgem Maria: "leva as tardes da eternidade a fazer meia". Sobre o Espírito Santo: “empoleira-se nas cadeiras e suja-as” (a tal pomba). Sobre o céu: “Tudo no céu é estúpido como a Igreja Católica./ (...) Mas os seres não cantam nada./ Se cantassem seriam cantores. Os seres existem e mais nada,/ E por isso se chamam seres". As imperfeições do ser e do não-ser são mostradas abertamente na poética de Caeiro. Alguns verbos dão o tom nessa estrofe: diz, escarrar, coça, empoleira, suja (os três últimos formam uma gradação verbal sobre o Espírito Santo); criou, duvido (questionamento da fé cristã), cantam, existem, chamam, adormece, levo, etc. Destaque para o verbo dizer, com forma pronominal, que repete-se várias vezes como se servisse para dar autenticidade aos fatos apresentados. No último verso dessa estrofe, o eu poético assume a guarda do menino Jesus: "E eu levo-o para casa".

A sétima estrofe, precedida por uma linha pontilhada, traz uma fartura de verbos de ligação e muitas conjunções aditivas. "Ele é a Eterna Criança, o deus que faltava. / Ele é o humano que é natural” (grifos meus). É curioso observar que na primeira parte do verso a palavra "deus" está em minúsculo e "Eterna Criança" em maiúsculo. Esse procedimento provoca uma inversão da eternidade materializada sob a forma de criança. Da mesma forma, quando essa humanização atinge um estado de sublimação - provocada no e pelo campo literário - no mesmo nível paradigmático do texto bíblico, o eu poético encontra nessa perfeição de ser o seu semelhante: "Ele é o humano que é natural,/ Ele é o 
divino que sorri e que brinca./ E por isso é que sei com toda a certeza/ Que ele é o Menino Jesus verdadeiro". A humanização consagrada do menino Jesus chega ao ponto dele afirmar que "é porque ele anda sempre comigo que eu sou poeta sempre". Curiosamente, na busca de marcas da modernidade, a primeira impressão que se tem é que parece que se está recuperando um mito literário - baseado na idéia aristotélica de que para escrever poesia é preciso de inspiração, complementada depois por Platão que disse ser necessário ter o domínio da técnica de fazer verso - concepção esta muito forte na época do romantismo. Esse mito, desde os simbolistas, praticamente deixou de existir. No entanto, em uma leitura mais atenta é possível perceber que é a proximidade com o ser infantil que faz do homem um poeta. Com essa proximidade ele está aberto a novos experimentos, à sublimação dos seres e das coisas. Seria como se possuísse o olhar de descobridor. Lembro-me do ensinamento do verso de Oswald: "aprendi com meu filho de 10 anos que a poesia é a descoberta das coisas que eu nunca vi”. Melhor dizendo, a partir dessa reação - as coisas vistas somente pelo olhar infantil - que surge esse eterno poeta. Aí é que está o elo da modernidade.

A estrofe seguinte começa com maiúsculas: "A Criança Nova que habita onde vivo/ Dá-me uma mão a mim/ (...) Que não há mistério no mundo/ E que tudo vale a pena" Este último verso dialoga com os famosos versos de "Mar portuguez", do livro Mensagem: "Valeu a pena? Tudo vale a pena/ Se a alma não é pequena" (idem, p.82). Trata-se de uma estrofe com tintura existencial, corrente filosófica que surgirá algumas décadas depois, todavia a literatura se nutre há muitos anos dessa fonte. "O mais filósofo dos heterônimos de Pessoa afirma não ter filosofia. Mero jogo retórico. A sua filosofia parte justamente da negação da própria fillosofia" (RAMOS, op.cit., p. 31).

$\mathrm{Na}$ seqüência, uma pequena estrofe de quatro versos: "A Criança Eterna acompanha-me sempre./ A direção do meu olhar é o seu dedo apontando" (grifos meus). Dois períodos sinestésicos descontraídos fecham essa estrofe: "O meu ouvido atento alegremente a todos os sons/ São as cócegas que ele me faz, brincando nas orelhas". No destaque, houve uma inversão do sujeito que antes havia sido apresentado como "Eterna Criança" e agora é a "Criança Eterna". Esse segundo sujeito, mais forte, está bem mais próximo e íntimo. A voz lírica metonimicamente se encanta pelo novo ser. 
Há um profundo sentimento de irmandade, de comunhão, de fraternidade, que se encaixa perfeitamente nos conceitos cristãos, em trecho da próxima estrofe: "Mas vivemos juntos e dois/ Com um acordo íntimo/ Como a mão direita e a esquerda". Lembro-me de um dito popular que diz: "eu te conheço tão bem como o olho direito conhece o esquerdo". É dessa maneira que o leitor convive com essa confidência, com esse conluio poético. Poucos, mas suficientes verbos de ação se apresentam: damo-nos, pensamos, vivemos (grifos meus). Essa gradação verbal estende uma situação anterior - já vivida em outros versos - e acentua a paz espiritual, fruto da visão humanizada. O sagrado nunca esteve relacionado no canto de Caeiro como algo posto, inatingível ou mesmo condenável pelos ensinamentos cristãos. É como se ele quisesse compor uma nova ordem, a ordem do texto poético da tessitura do material que eleva. Ele procura e recupera a ordem estabelecida entre Deus e o homem. Isso não significa ter que abrir mão do terreno espiritual e optar pelo plano terreno ou vice-verso. O poema todo tenta fugir do modelo mítico ou de qualquer outro paradigma.

"Ao anoitecer brincamos as cinco pedrinhas/ No degrau da porta de casa,/ Graves como convém a um deus e a um poeta,/ E como se cada pedra/ Fosse todo um universo/ E fosse por isso um grande perigo para ela/ Deixá-la cair no chão" (grifos meus). É nesse espaço lúdico e temporal, alimentado por um ambiente familiar, que Caeiro atira suas pedrinhas personificadas - "brincamos as cinco pedrinhas" - como se fosse um jogo de amarelinhas e que para passar para outra fase fosse preciso pular de casa em casa, de verso em verso.

A estrofe seguinte prepara um ritual de passagem para o encerramento do canto: "Depois eu conto-lhe histórias das cousas só dos homens/ E ele sorri, porque tudo é incrível./ Ri dos reis e dos que não são reis,/ E tem pena de ouvir falar das guerras,/ E dos comércios, e dos navios/ Que ficam fumo no ar dos altos-mares". As epopéias antigas cantavam os feitos dos heróis e das grandes nações. Camões fez isso magistralmente em $O s$ Lusíadas para saudar o povo português, sem abrir mão da crítica. (Lembro-me dos episódios do gigante Adamastor, do velho do Restelo). Fernando Pessoa, em Mensagem, fez uma releitura épico-moderna: "Ó mar salgado, quanto do teu sal São lágrimas de Portugal!" (idem, p.82). Um dito antigo dizia: "Está feliz como um rei. Está rindo de 
barriga cheia". É com esse mesmo espírito que o menino quer viver. Rir com todos e para todos. Depois de ouvir tantas estórias: "Levo-o ao colo para dentro de casa/ E deito-o, despindo-o lentamente/ E como seguindo um ritual muito limpo/ E todo materno até ele estar nu". A impressão que se tem é que o eu poético assumiu o papel da Virgem Maria. Mas essa mulher assexuada não guarda um mistério, não se cobre de luz, pelo contrário, investe-se tão somente do exercício de acalentar uma pequenina alma. A referência à nudez aqui permeia o próprio texto bíblico, no entanto não tem a intenção de mostrar a abdicação dos bens materiais. O que se procura mesmo é o acalento materno e poético. A luz que vem ou se acende é onírica e, ao mesmo tempo, lúdica: "E brinca com os meus sonhos. / Vira uns de pernas para o ar,/ Põe uns em cima dos outros/ E bate as palmas sozinho/ $\underline{\text { Sorrindo }}$ para o meu sono" (grifos meus). Novamente aparece uma gradação verbal, desta vez provocando um efeito imagético, sinestésico e, ao mesmo tempo, metafórico.

As duas últimas estrofes são precedidas de linhas pontilhadas, como que a dar espaço imagético para o leitor. A lírica contemplada substitui a visão sacralizada. Isso pode ser notado nos versos: "Pega-me tu ao colo/ E leva-me para dentro da tua casa./ Despe o meu ser cansado e humano/ E deita-me na tua cama". O eu poético quer desfrutar das mesmas expectativas, que são humanas, não divinas; que são sagradas pelo texto poético e, por isso, profanas, todavia sem imolar a fé. "Esta é a história do meu Menino Jesus. Por que razão que se perceba/ Não há de ser ela mais verdadeira/ Que tudo quanto os filósofos pensam/ E tudo quanto as religiões ensinam? (grifos meus)" Caeiro sagra o texto literário ao tornar seu Menino Jesus no que todos gostariam de ter e conhecer. Eis o mistério da poesia encarnada. O sacro e o profano são feitos da mesma matéria. A mesma poesia que anuncia é a que ergue a voz do poema. A palavra na modernidade é um dos símbolos da decantação entre a tradição e a ruptura, que não é processo é passagem. É, sobretudo, o levante da imagem poética estabelecida pelo paganismo superior de Alberto Caeiro, mestre de Fernando Pessoa e seus heterônimos. O sagrado e o profano nunca estiveram tão próximos com a humanização de Cristo. A mesa dos versos está posta. A ceia será servida. 


\section{REFERÊNCIAS BIBLIOGRÁFICAS}

BERARDINELLI, Cleonice. Estudos de Literatura Portuguesa. Imprensa Nacional - Casa da Moeda, 1985. p.263.

BÍBLIA SAGRADA AVE MARIA. Revisada por Frei José Pedreira de Castro, O.F.M., e pela equipe auxiliar da Editora. 135.ed. São Paulo: Ave-Maria, 2000. p.1286.

FRIEDRICH, Hugo. Estrutura da lírica moderna (da metade do século XIX a meados do século XX). Trad. Marise M. Curioni. 2.ed. São Paulo: Livraria Duas Cidades, 1991.

GAMA, Rinaldo. O Guardador de Signos: Caeiro em Pessoa. São Paulo: Perspectiva: Instituto Moreira Sales, 1995. (Debates, 269)

GARCEZ, Maria Helena Nery. "Uma poética grávida de impactos". In: Literatura Portuguesa: História, memória e perspectivas. (org.) Aparecida de Fátima Bueno, Anni Gisele Fernandes et al. São Paulo: Alameda, 2007.

LIND, George Rudolf. "B. Alberto Caeiro, O renovador do paganismo". In:---Estudo sobre Fernando Pessoa. Imprensa Nacional - Casa da Moeda, s/d. p.109.

LOURENÇO, Eduardo. O Labirinto da Saudade: Psicanálise Mítica do Destino Português. 4.ed. Lisboa: Publicações Dom Quixote, 1991.

NUNES, Benedito. "Fernando Pessoa”. In: O dorso do tigre. São Paulo: Perspectiva, 1968. pp.213-262.

PESSOA, Fernando. Obra Poética. (org.) Maria Aliete Galhoz. 3.ed. Rio de Janeiro: Nova Aguilar, 1998.

RAMOS, Isaac N. A. "Confluências, divergências e singularidades". In: Ensaios de Literatura Comparada: Portugal, Brasil, Angola, Cabo Verde. (org.) Isaac Newton Almeida Ramos \& Agnaldo Rodrigues. Cáceres-MT: Unemat Editora, 2004.

SEGOLIN, Fernando. "Caeiro e Nietzsche: Da Crítica da Linguagem à Anti-filosofica e à Antipoesia". In: Actas do IV Congresso Internacional de Estudos Pessoanos - Seção Brasileira, vol.II. Vários autores, 2 vols. Porto, Fundação Eng. António de Almeida/Fundação Calouste Gulbenkian, 1989. 